\title{
Knowledge, Attitudes and Use of Emergency Contraceptives among Female Students of the University of Nigeria, Nsukka
}

\author{
Kosisochi Chinwendu Amorha, Patience Ijele Adayi, \\ Ebere Emilia Ayogu, Chinwe Victoria Ukwe \\ (Department of Clinical Pharmacy and Pharmacy Management, Faculty of Pharmaceutical Sciences, University \\ of Nigeria, Nsukka, Enugu State, Nigeria)
}

\begin{abstract}
Emergency contraception prevents pregnancy after unprotected sex or contraceptive failure. The objective of the study was to assess the knowledge, attitude and use of emergency contraceptives among female undergraduates in the University of Nigeria, Nsukka (UNN). This study was a cross-sectional, descriptive survey conducted among female undergraduates in UNN from June to August 2016. Data were collected by the 34-item structured, self-administered questionnaires and analyzed using the IBM Statistical Product and Service Solutions (SPSS) Statistics for Windows, Version 20.0 (IBM Corp, Version 20.0, Armonk, NY, USA). A total of 635 questionnaires were completed and returned (63.5\% participation rate). Overall, $40 \%$ of the students had adequate knowledge of emergency contraceptives (ECS) while $85.4 \%$ had positive attitudes towards ECs. About $70 \%$ were recommended ECs by friends/partners, mostly for withdrawal fail $(32.0 \%)$. Sixth year students had significantly better knowledge on ECs than second $(P=0.035)$, third $(P=0.020)$ and fourth year students $(P=$ $0.022)$ respectively. More pharmacy students had adequate knowledge of ECs (61.3\%) compared to the other faculties $(P=0.011)$. Although majority of the students had positive attitudes towards EC use, less than half had adequate knowledge. The two major sources of information on ECs were formal education and the internet. Students in higher years of study had better knowledge on ECs and pharmacy students were the most knowledgeable. About half of the respondents had unprotected sex in the past with a similar percentage using ECs mostly recommended by their friends or partners.
\end{abstract}

Keywords: attitudes, emergency contraceptives, knowledge, use, University of Nigeria Nsukka

\section{Introduction}

Emergency contraception (EC), also called post-coital contraception, is not administered for regular contraception but to prevent pregnancy after unprotected sex or contraceptive failure [1,2]. Majority of the pregnancies that occur in Nigeria are unplanned and unwanted [3]. Unintended child births and unsafe abortions can be reduced by EC through the prevention of unintended pregnancies $[1,4]$. Unsafe abortions account for up to $13 \%$ of pregnancy-related deaths worldwide (1). Nigeria had an estimated 1.25 million induced abortions in 2012 [5]. Induced abortion is illegal in Nigeria, except when performed to save a woman's life [5].

The failure of barrier methods such as slippage, condom breakage or misuse, rape, failed coitus interruptus, two or more consecutive missed oral contraceptive pills, or unexpected sexual intercourse could prompt the use of EC [1]. Some methods of EC include: emergency contraceptive pills (ECPs), intrauterine contraceptive devices and mifeprostone [1]. ECPs should be taken within 72 hours after unprotected intercourse [2].

In many countries, EC is underused [1]. Although adolescents may be sexually active, the fear of stigma, shame and embarrassment, little or no knowledge of contraceptives, unplanned sexual activities, and attitude of healthcare providers may deter them from utilizing contraceptives [6]. These may lead to unintended pregnancies causing discontinuation of school and repeat abortions [1,7]. The rate of women seeking repeat abortions is high in Nigeria, in spite of available contraceptive services [7]. The general objective of the study was to assess the knowledge, attitude and use of emergency contraceptives among female undergraduates in the University of Nigeria, Nsukka (UNN). Data generated from this study will assist universities in Nigeria in developing strategies to promote the informed use of emergency contraceptive pills.

\section{Methods}

This study was a descriptive cross-sectional study conducted from June to August 2016, to assess the knowledge, attitude and use of emergency contraceptives among female undergraduates in UNN, Southeast Nigeria.The University of Nigeria Nsukka has two major campuses, the Nsukka campus and Enugu Campus. The Nsukka Campus of UNN is located on 871 hectares of hilly savannah in the town of Nsukka about eighty kilometers north of Enugu State. As of 2015, the student population of this campus was 15,439, consisting of 8,690 males and 6,749 females. The Nsukka Campus has the faculties of Arts, Agriculture, Biological Sciences, 
Education, Engineering, Pharmaceutical Sciences, Physical Sciences, Social Sciences and Veterinary Medicine, as well as Postgraduate and Sandwich Programmes. The study participants were second to final year undergraduate students of the University of Nigeria, Nsukka Campus, willing and able to participate. First year students and male students of the Nsukka campus were excluded from the study. Also, all students and members of staff of the University of Nigeria Enugu Campus (UNEC) did not participate.

The total population of students was obtained from the Department of Academic Planning Unit, UNN. From this sampling frame, the sample size was determined using the Raosoft ${ }^{\circledR}$ sample size calculator to be 356 at $95 \%$ confidence interval and 5\% margin of error, assuming 50\% of the participants responded. The multistage sampling method was utilized. For convenience of sampling, the sample size was increased to 1000 . In the first stage, stratified random sampling was used to determine the number of female students to participate in each faculty. This number was further stratified into the various departments in each faculty. Then, simple random sampling was used to select the participants in the various levels in each department in the different faculties.

Oral and written consent were obtained from the study participants prior to questionnaire distribution. A 34- item structured self- administered questionnaire was disseminated to the participants to assess demographic information, sexual history, as well as their knowledge, attitude and use of emergency contraception. To ensure quality of the data, questions were adapted from previously conducted studies and changes made, based on the local context [8,9]. The questionnaire was validated from the responses of respondents who were not included in the study. The selected participants filled the questionnaires in their classes, within 10 minutes, without the consultation of any reference material. Confidentiality was maintained as the names of the respondents were not requested for.

Data were coded and analyzed using the IBM Statistical Product and Service Solutions (SPSS) Statistics for Windows, Version 20.0 (IBM Corp, Version 20.0, Armonk, NY, USA). Descriptive statistics were used to summarize data. The independent t-test and analysis of variance (ANOVA) were utilized to determine the differences between the demographic variables in their mean knowledge and attitude scores. The Pearson chi-square test showed the association and relationship between variables. For all results, $p$-value $\leq 0.05$ was considered statistically significant.

Before commencement of this research, approval was obtained from the Health Research and Ethics Board of the University of Nigeria Teaching Hospital (UNTH), Ituku-Ozalla, Enugu State. The study participants were informed about the objectives of the study; confidentiality of their responses; their right not to partake in the study; their freedom to withdraw anytime or not to answer any of the questions.

\section{Results} $(635 / 1000)$

A total of 635 questionnaires were completed and returned, representing a participation rate of $63.5 \%$

About $87 \%$ of the students were less than 25 years and majority were single (90.9\%). More than half were Nigerian (98.9\%), Roman Catholic (50.3\%), from monogamous families (91.9\%), grew up in the SouthEast $(60.5 \%)$ and resided in hostels on campus (68.9\%). Other information on demographic details are shown in Table 1.

The two major sources of information on ECs were formal education (35.4\%) and the internet (24.1\%). Most students felt ECs can be obtained from community pharmacies (59.1\%). Overall, only $40 \%$ of the students had adequate knowledge of emergency contraceptive. Table 2 also shows the individual knowledge questions and the students' response to each question.

About $85.4 \%$ had positive attitudes (attitudes that encourage the use of emergency contraceptives) towards emergency contraceptives, as seen in Table 3 .

In table 4 , close to $40 \%$ of the students had had sex before, majorly between ages, $19-24$ years with more than half $(57.1 \%)$ having had unprotected sexual intercourse in the past. About $70 \%$ were recommended ECs by friends or partners, mostly for withdrawal fail (32.0\%).

In table 5 , there was a statistically significant difference $(\mathrm{P}=0.015 ; \mathrm{F}=2.391)$ between the mean knowledge scores for the faculties. However, the Post Hoc multiple comparisons with Scheffe did not show the pattern of the difference. Also, there was a statistically significant difference $(\mathrm{P}=0.001 ; \mathrm{F}=5.509)$ between the mean knowledge scores for the different years of study. The Post Hoc multiple comparisons with Scheffe showed a significant difference between sixth year students and second year students $(P=0.035)$; third year students $(P=0.020)$ and fourth year students $(P=0.022)$. However, there was no significant difference in the mean knowledge scores between fifth and sixth year students. Since higher scores on knowledge indicate better knowledge on ECs, sixth year students had significant better knowledge on ECs than second, third and fourth year students respectively.

In table 6, a proportionately much larger number of students in the Faculty of Pharmaceutical Sciences had adequate knowledge of ECs (61.3\%) compared to the other faculties, most of which had below $50 \%$. 


\section{Discussion}

This study revealed that less than half of the students had adequate knowledge of ECs. Although more than three-quarter had attitudes that encouraged the use of ECs, only about half of those who had lost their virginity had used ECs before.

Knowledge scores were summed up to give the total knowledge score for each respondent. Knowledge scores ranged from 11 (minimum) to 22 (maximum). These knowledge scores were categorized such that those who scored above the median (15) of the total knowledge scores had good knowledge of emergency contraceptives. Also, the attitude scores were summed to give the total attitude score for each respondent with range from 8 (minimum) to 16 (maximum). Respondents who had above the median, 11, of the total attitude scores were categorized as having positive attitudes.

Majority of the students obtained their information on EC from formal settings with the internet and friends following closely behind. This is similar to a study amongst Ethiopian female undergraduates where health facilities accounted for $69.3 \%$ of the sources of information on ECs and $78.3 \%$ believed that ECs should be obtained from health institutes [4]. Few students obtaining information from families or relatives may stem from parents/guardians failing to give their children or wards information on contraception either due to sociocultural or religious beliefs. Some young people who get pregnant have an induced abortion because of fear of their parents' reaction necessitating the relevance of parent-child communication about sexual issues [10]. Worthy of note is that informal sources of information on health issues may be misleading and the internet serves as a reservoir for all kinds of information. However, in a Jamaican study informal networks were the largest source of information on EC and most of the students who explored them had correct knowledge about the general characteristics of ECPs [1]. Thus, informal sources need to be verified, if informed decisions are to be made.

About two-fifth of the students had adequate knowledge of ECs. Although this was below average, it was higher than a study among students in University of Buea, Cameroon; Adama University, Ethiopia; and three tertiary institutions in Dessie, Ethiopia where only $7.2 \%, 27.2 \%$ and $33.9 \%$ had adequate knowledge of ECPs, respectively $[1,11,12]$ but lower than a study in Wachamo University, Ethiopia where $49.8 \%$ had good knowledge of ECPs [13]. In our findings, few students knew that EC should be taken when there is a missed pill or when there is failure of contraception. Less than half knew when ECPs were effective or the recommended number of doses/time between doses. These findings are supported by a study conducted among female nonmedical students in Anambra State University, South-Eastern Nigeria where poor basic knowledge of emergency contraception and poor knowledge of correct methods and timing of the agents were reported [14]. Another study in Ethiopia concluded that although more than half (69.9\%) of the students knew about emergency contraception, only $27 \%$ of them felt confident that they understood when it was most effective and only $32.1 \%$ indicated correctly that ECPs should be taken within 72 hours [11]. In another study in South-West Ethiopia, only $28.3 \%$ of the students knew the correct time of administration of ECPs [8]. A study among female university students in KwaZulu-Natal, South Africa also documented poor knowledge of EC as $29.7 \%$ did not know the right time limits for use [15]. Also, in a study in Uganda about $42 \%$ of the students did not know the time interval within which ECPs can work and one third thought it would interrupt an ongoing pregnancy [10]. Women with poor knowledge might less likely use EC compared to the knowledgeable ones [16]. The confusion on how to take ECPs may be caused by students purchasing ECPs hurriedly and feeling too embarrassed to ask questions [17]. These students may even reject counselling or send others to buy it for them [17]. Health professionals should be aware of these and emphasize the correct timing when ECs are prescribed, dispensed or administered in order to enhance their effectiveness. Students who wish to dash out of pharmacies without advice on EC use for fear of being seen should be encouraged to go through the leaflet before use. Thus, leaflets should be easy-to-understand.

Majority of the students in our study had positive attitudes towards ECs, a lot higher than two Ethiopian studies where only close to $50 \%$ of the students had a favourable attitude towards EC [8, 13]. This favourable disposition might be due to knowledge about those who have had unwanted pregnancies with the possible consequences of abortions or even death.

More than half of the students believed that EC promotes promiscuity. About half of the students thought EC is a way of abortion with about four-fifth believing that EC may hurt the baby if it does not work. In another study, more than half of the Cameroonian students thought ECP was a form of abortion, compared to $25.8 \%$ of university students in Ghana and $49 \%$ of nursing students in Kenya [1]. Confusing EC with induced abortion may negatively affect the acceptability of the method. This is particularly so in countries like Nigeria where abortion is illegal. Levonorgestrel has been shown not to interfere with an established pregnancy or with the outcome of pregnancy [10].

Most of the students felt that people have a wrong impression when they see one purchasing an EC. Some students perceive the importance of ECs is post-rape [4]. Thus, a female student purchasing an EC may be thought of as either being promiscuous or sexually assaulted. The fear of being seen by others may hinder the 
use of ECs [8]. In another study, students were asked whether they thought ECPs should be sold over-thecounter (OTC) without prescription and $63.4 \%$ were not in favour of OTC use with moral decay given as one of the reasons [10]. A different study found that religious beliefs may also hinder the provision of emergency contraception [6]. Also, some healthcare providers believe that providing contraceptives for unmarried adolescents promotes sexual promiscuity and this class of people should be asked to abstain from sex [18]. Besides stigma, the non-availability of ECs in community pharmacies, for whatever reason, may hinder its use by those who need them [11].

This study revealed that about two-fifth of the students had engaged in sex and a little above half had unprotected sexual intercourse. Most of them were recommended ECs by friends or partners, majorly for withdrawal fail. High levels of premarital sexual activity without the use of contraceptives have been recorded among Nigerian adolescents [18]. In a study in a private university in Nigeria, $44.7 \%$ of the female students had lost their virginity and $34.0 \%$ were sexually active [9]. This is not different from other African countries. In a study among the female students in KwaZulu-Natal, South Africa, 53.2\% reported to have sex, and $21.2 \%$ of the sexually experienced students used EC prior to the study [15]. A study among Ethiopian undergraduate female students showed $23.4 \%$ of the respondents were sexually active; $9.8 \%$ of those who were sexually active had had unprotected sexual intercourse before [4]. In a study in Botswana, more than half of the students indicated that they had engaged in sexual acts [19]. In a Ugandan study about $70 \%$ of the undergraduate female students had ever engaged in sexual intercourse and $62.1 \%$ reported having sex in the past 12 months [20].

Premarital sexual activity is high in African countries. A study among female undergraduate students in Southwest Nigeria indicated a high level of sexual activity and low contraceptive use [21]. Even teenage sexual activity is rampant. A study at Jimma University specialized hospital, southwest Ethiopia revealed that pregnancy among women of 15-19 years was very common likely due to the low knowledge and practice of emergency contraception despite high positive attitude towards emergency contraceptives [22]. A study to test the knowledge and use of EC among students of public secondary schools in Ilorin, Nigeria showed that $30 \%$ had ever had sex out of which approximately 43\% ever used EC [23]. An Ethiopian study indicated that $84.4 \%$ of the total respondents had a favourable attitude toward sexual relationships [11]. The university and its environs offer many students the opportunity to be more independent, make new friends and, for some, to experience sexual relationships [11]. In the University of Nigeria Nsukka, those who reside off-campus may have fewer restrictions compared to those who reside in hostels on campus. For instance, female students on campus have no-visit periods; hostels are shut by $9 \mathrm{pm}$ and males are not allowed to spend the night. There is more liberty off-campus as these restrictions are non- existent and these students may be more sexually-active. The off-campus population has been growing in recent years.

Many of the respondents lost their virginity between the ages of 19 to 24 years, most likely as university students. Thus, there is need for undergraduates to be taught on sexual health. This should include abstinence from sex or safe sex and the need to make informed decisions on the use of ECs. It could be included in the curriculum of undergraduate students from first year. There could also be periodic seminars, workshops, trainings or health education programmes sponsored by the university, health related faculties, the university teaching hospital, medical centre or non- governmental organizations to ensure that students are making well informed decisions on sex. Targeted campaigns could be implemented close to or during international days such as Valentine's Day when students are more likely going to indulge in sex.

Although there was no significant difference in the mean knowledge scores between fifth year and sixth year students, the sixth year students had significantly better knowledge on ECs than second, third and fourth year students respectively. This finding is supported by another study where knowledge about emergency contraception increased with advancing years of study and students in higher years were more likely to have a favourable attitude toward sex [11]. Students in higher years of study are more likely older than those in lower years and probably, with more experience. These students may be more exposed to sexual education and practices. Also, the sixth year students were all in Veterinary Medicine. Besides their longer stay on campus, they are involved with medical courses.

A proportionately much larger number of students in pharmacy had adequate knowledge of ECs compared to the other faculties. This could be due its inclusion in their curriculum. However, there may be the need for it to be included in the curriculum of non-medical students possibly through the General Studies courses. University students in Nigeria are usually taught topics outside their specialty through this means.

This study had some limitations. It was conducted in the Nsukka Campus of the University of Nigeria, Nsukka and the results may not be the same in other campuses or universities. Some students may have been unwilling to participate due to the sensitive study subject despite the prior information that confidentiality was to be maintained. Furthermore, it was difficult to locate students in departments that lacked classrooms. 


\section{Conclusion}

Although majority of the students had positive attitudes towards the use of ECs, less than half had adequate knowledge. The two major sources of information on ECs were formal education and the internet. Students in higher years of study had better knowledge on ECs and pharmacy students were the most knowledgeable. About half of the students had unprotected sexual intercourse in the past with a similar percentage using ECs mostly recommended by their friends or partners.

There is the need to improve university students' informed and timely use of emergency contraception to prevent unwanted pregnancies that may impede their education and career prospects as well as take a large toll on their health. Students should be informed that although emergency contraception may prevent pregnancy, it does not protect against sexually transmitted infections.

\section{References}

[1]. E.J. Kongnyuy, P. Ngassa, N. Fomulu, C.S. Niysonge, L. Kouam, and A.S. Doh. A survey of knowledge, attitudes and practice of emergency contraception among university students in Cameroon, BMC Emergency Medicine. 7(7), 2007.

[2]. S. Young, B. Griffin, and K. Vest. Active-Learning Instruction on Emergency Contraception Counseling, American Journal of Pharmaceutical Education, 77(5), 2013, Article 104

[3]. H. Ameha, and F.Nebreed. Emergency contraception: potential clients and providers perspectives, Ethiopian Journal of Health Sciences, 16(1), 2006, 2-5.

[4]. F.A. Ahmed, K.M. Moussa, K.O. Petterson, and B.O. Asamoah. Assessing knowledge, attitude, and practice of emergency contraception: a cross-sectional study among Ethiopian undergraduate female students, BMC Public Health. 12, 2012, 110.

[5]. A. Bankole, I.F. Adewole, R. Hussain, O. Awolude, S. Singh, and J.O. Akinyemi. The incidence of abortion in Nigeria. International Perspectives on Sexual and Reproductive Health, 41(4), 2015, 170-181.

[6]. D.E. Ball, N. Marafie, and E. Abahussain. Awareness and perceptions of emergency contraception among retail pharmacists in Kuwait. Pharmacy World and Science, 28(2), 2006, 101-106.

[7]. M.A. Lamina. Prevalence of abortion and contraceptive practices among women seeking repeat induced abortion in Western Nigeria. Journal of Pregnancy, 2015, 2015, 1-7, Article ID 486203.

[8]. B.Z. Shiferaw, B.T. Gashaw, and F.Y. Tesso. Factors associated with utilization of emergency contraception among female students in Mizan-Tepi University, South West Ethiopia. BMC Research Notes, 8, 2015, 817.

[9]. J.O. Awoleke, A.J. Adanikin, A. Awoleke, and M. Odanye. Awareness and practice of emergency contraception at a private university in Nigeria. BMC Research Notes, 8, 2015, 215.

[10]. J.K. Byamugisha, F.M. Mirembe, E. Faxelid, and K. Gemzell-Danielsson. Emergency Contraception and Fertility awareness among University Students in Kampala, Uganda. African Health Sciences, 6(4), 2006, 194-200.

[11]. W.T. Nibabe, and T. Mgutishini. Emergency contraception amongst female college students - knowledge, attitude and practice. African Journal of Primary Health Care and Family Medicine, 6(1), 2014, 1-7.

[12]. D. Tilahun, T. Assefa, and T. Belachew. Knowledge, attitude and practice of emergency contraceptives among Adama university female students. Ethiopian Journal of Health Sciences, 20(3), 2010, 195-202.

[13]. T.G. Hailemariam, T. Tesfaye, T. Melese, W. Alemayahu, Y. Kenore, Y. Lelamo, et al. Awareness and practice of emergency contraception at a private university in Nigeria. BMC Research Notes, $8,2015,112$.

[14]. I.U. Ezebialu, and A.C. Eke. Knowledge and practice of emergency contraception among female undergraduates in south eastern Nigeria. Annals of Medical and Health Sciences Research, 3, 2013, 541-545.

[15]. M.E. Hoque, and S. Ghuman. Knowledge, practices, and attitudes of emergency contraception among female university students in Kwazulu-Natal, South Africa. PLOS ONE, 7(9), 2012, e46346. doi:10.1371/journal.pone.0046346.

[16]. M. Abate, N. Assefa, and T. Alemayeha. Knowledge, attitude, practice, and determinants of emergency contraceptive use among women seeking abortion services in Dire Dawa, Ethiopia, PLoS ONE, 9(10), 2014, e110008. doi:10.1371/journal.pone.0110008.

[17]. R. Both, and F. Samuel. Keeping silent about emergency contraceptives in Addis Ababa: a qualitative study among young people, service providers, and key stakeholders. BMC Women's Health, 14, 2014, 134

[18]. E.L. Ahanonu. Attitudes of healthcare providers towards providing contraceptives for unmarried adolescents in Ibadan, Nigeria. Journal of Family Reproductive Health, 8(1), 2013, 33-40.

[19]. M.E. Hoque, T. Ntsipe, and M. Mokgathe-Nthabu. Awareness and practices of contraceptive use among university students in Botswana. Sahara Journal, 10(2), 2013, 83-88.

[20]. H. Nsugba, J.N. Sekandi, H. Sempeera, and F.E. Makunbi. Contraceptive use, knowledge, attitude, perceptions and sexual behavior among female University students in Uganda: a cross-sectional survey. BMC Women's Health, 16, 2016, 6.

[21]. A.A. Akintayo, O.O. Akin-Akintayo, A.I. Adanikin, I.P. Ade-Ojo. Sexual and contraceptive practices among female undergraduates in a Nigerian tertiary institution. Ethiopian Journal of Health Sciences, 25(3), 2015, 209-216.

[22]. T. Tesfaye, T. Tilahun, and E. Girma. Knowledge, attitude and practice of emergency contraceptive among women who seek abortion care at Jimma University specialized hospital, southwest Ethiopia. BMC Women's Health, 12, 2012, 3 .

[23]. O.A. Babatunde, D.O. Ibirongbe, O. Omede, O.O. Babatunde, K.A. Durowade, A.G. Salaudeen, et al. Knowledge and use of emergency contraception among students of public secondary schools in Ilorin, Nigeria. Pan African Medical Journal, 23, $2016,74$. 
Knowledge, Attitudes and Use of Emergency Contraceptives among Female Students of the University

Tables: The tables are attached.

Table 1: Demographic details

\begin{tabular}{|c|c|}
\hline Variables & $\mathbf{n}(\%)$ \\
\hline \multicolumn{2}{|l|}{ Age (in years) } \\
\hline $16-19$ & $98(16.1)$ \\
\hline $20-24$ & $433(71.0)$ \\
\hline $25-29$ & $67(11.0)$ \\
\hline$\geq 30$ & $12(2.0)$ \\
\hline \multicolumn{2}{|l|}{ Faculty } \\
\hline Agriculture & $54(8.5)$ \\
\hline Ants & $133(209)$ \\
\hline Biological Sciences & $116(18.3)$ \\
\hline Education & $88(139)$ \\
\hline Engineering & $17(2.7)$ \\
\hline Pharmaceutical Sciences & $62(9.8)$ \\
\hline Physical Sciences & $18(2.8)$ \\
\hline Social Sciences & $127(20.0)$ \\
\hline Veterinary Medicine & $20(3.1)$ \\
\hline \multicolumn{2}{|l|}{ Year of Study } \\
\hline 2nd Year & $215(339)$ \\
\hline 3rd Year & $169(26.6)$ \\
\hline 4 th Year & $213(33.5)$ \\
\hline 5th Year & $33(5.2)$ \\
\hline 6th Year & $5(0.8)$ \\
\hline \multicolumn{2}{|l|}{ Nationality } \\
\hline Nigerian & $627(989)$ \\
\hline Non-Nigerian & $6(09)$ \\
\hline \multicolumn{2}{|l|}{ Religion } \\
\hline Muslim & $24(39)$ \\
\hline Roman Catholic & $309(50.3)$ \\
\hline Protestant & $137(22.3)$ \\
\hline Others & $143(23.3)$ \\
\hline \multicolumn{2}{|l|}{ Marital Status } \\
\hline Single & $566(909)$ \\
\hline Cohabit with boyfriend & $25(4.0)$ \\
\hline Married & $28(45)$ \\
\hline Separated/Divorced & $4(0.6)$ \\
\hline \multicolumn{2}{|l|}{ Family Setting } \\
\hline Monogamous & $556(919)$ \\
\hline Polygamous & $41(6.8)$ \\
\hline Separated & $5(0.8)$ \\
\hline Divorced & $3(0.5)$ \\
\hline \multicolumn{2}{|c|}{ Place of Childhood Upbringing } \\
\hline South West & $115(18.6)$ \\
\hline South East & $373(60.5)$ \\
\hline South South & $48(7.8)$ \\
\hline North West & $17(2.8)$ \\
\hline North East & $28(4.5)$ \\
\hline North Central & $36(5.8)$ \\
\hline \multicolumn{2}{|l|}{ Residence } \\
\hline Hostel & $430(689)$ \\
\hline Off-campus & $194(31.1)$ \\
\hline
\end{tabular}

Table 2: Respondents' source of information on emergency contraceptives; where they feel they can be obtained and knowledge of emergency contraceptives

\begin{tabular}{|l|l|}
\hline Variables & Yes (\%) \\
\hline Source of information on emergency contraceptives & \\
\hline Formal Education & $225(35.4)$ \\
\hline Media & $117(18.4)$ \\
\hline Books/Magazines & $80(12.6)$ \\
\hline Intemet & $153(24.1)$ \\
\hline Health Facilities & $55(8.7)$ \\
\hline Frends/Peers & $134(21.1)$ \\
\hline Family/Relatives & $30(4.7)$ \\
\hline None & $27(4.3)$ \\
\hline Where emergency contraceptives can be obtained & \\
\hline Hospital & $141(22.2)$ \\
\hline Pharmacy & $375(59.1)$ \\
\hline Chemist Shop/Patent Medicine Store & $152(23.9)$ \\
\hline Supermarket & $25(3.9)$ \\
\hline Impossible to obtain & $19(3.0)$ \\
\hline Knowledge of emergency contraceptives & Number of Correct \\
\hline Emergency contraceptive pills are the same as "moming after pills" (Yes) & Responses (\%) \\
\hline Drugs used as emergency contraceptives (Progesterone-only pill and IUCD) & $213(33.5)$ \\
\hline Emergency contraception protects from sexually transmitted infection (No) & $213(33.5)$ \\
\hline Situations that emergency contraceptives should be taken & $470(74.0)$ \\
\hline If a condom ruptured during intercourse (Yes) & \\
\hline When there is a missed pill (Yes) & $343(54.0)$ \\
\hline When forced to have sex or rape (Yes) & $76(12.0)$ \\
\hline When there is failure of contraception (Yes) & $367(57.8)$ \\
\hline To prevent pregnancy (Yes) & $53(8.3)$ \\
\hline When emergency contraceptive pills are effective (Within 72 hrs after sex) & $431(67.9)$ \\
\hline Recommended number of doses of emergency contraceptive pills (Two doses) & $232(36.5)$ \\
\hline $\begin{array}{l}\text { Recommended time between the doses of emergency contraceptive pills (12 hrs } \\
\text { apart) }\end{array}$ & $107(16.9)$ \\
\hline IUCD = Intra-uteine Contraceptive Device & \\
\hline
\end{tabular}

IUCD = Intra-uterine Contraceptive Device 
Knowledge, Attitudes and Use of Emergency Contraceptives among Female Students of the University

Table 3: Attitudes towards emergency contraceptives

\begin{tabular}{|c|c|c|c|c|}
\hline Variables (type of attitude) & & A & & \\
\hline $\begin{array}{l}\text { All females have the right to access emergency contraception } \\
\text { (positive) }\end{array}$ & $\begin{array}{l}190 \\
(30.5)\end{array}$ & $\begin{array}{ll}221 \\
(35.5)\end{array}$ & $145(23.3)$ & $66(10.6)$ \\
\hline $\begin{array}{l}\text { Provision of emergency contraception after an episode of } \\
\text { unprotected sex can prevent unwanted pregnancy (positive) }\end{array}$ & $\begin{array}{l}135 \\
(22.0)\end{array}$ & $\begin{array}{l}359 \\
(58.5)\end{array}$ & $88(14.3)$ & $32(5.2)$ \\
\hline Emergency contraception promotes promiscuity (negative) & 181 & 232 & $151(25.2)$ & $36(6.0)$ \\
\hline Emergency contraception is one way of abortion (negative) & $\frac{90.42}{122}$ & 192 & $211(35.8)$ & $64(10.9)$ \\
\hline $\begin{array}{l}\text { Emergency contraception mainly eauses infertility in a woman } \\
\text { (negative) }\end{array}$ & $\frac{20.61)}{75(12.8)}$ & $\begin{array}{l}232.0) \\
231 \\
(39.6)\end{array}$ & $224(38.4)$ & $54(9.2)$ \\
\hline It is a sinful act to use emergency contraception (negative) & $\begin{array}{l}103 \\
(17.5)\end{array}$ & $\begin{array}{l}170 \\
(28.9)\end{array}$ & $242(41.1)$ & $74(12.6)$ \\
\hline $\begin{array}{l}\text { Emergency contraception may hurt the baby in case it does not } \\
\text { work (negative) }\end{array}$ & $\begin{array}{l}218 \\
(36.3)\end{array}$ & $\begin{array}{l}280 \\
(46.7)\end{array}$ & $78(13.0)$ & $24(4.0)$ \\
\hline $\begin{array}{l}\text { People have a wrong impression when they see one purcha sing an } \\
\text { emergency contraceptive (negative) }\end{array}$ & $\begin{array}{l}328 \\
(53,3)\end{array}$ & $\begin{array}{l}244 \\
(39.7)\end{array}$ & $29(4,7)$ & $13(2,1)$ \\
\hline
\end{tabular}

SA - strongly agree; $\mathbf{A}$ - agree; $\mathbf{D}$ - disagree; SD - strongly disagree

Table 4: Sexual history and use of emergency contraceptives

\begin{tabular}{|l|l|}
\hline Variables & Yes (9) \\
\hline Sexual history: & \\
\hline I have had sex before & $225(38.7)$ \\
\hline Age (in years) at first sex & $15(6.9)$ \\
\hline$<13$ & $57(26.1)$ \\
\hline $13-18$ & $138(63.3)$ \\
\hline $19-24$ & $6(2.8)$ \\
\hline $25-30$ & $2(0.9)$ \\
\hline$>30$ & $125(57.1)$ \\
\hline Ihave had unprotected sexual intercourse & $30(14.0)$ \\
\hline I have had unwanted pregnancy & \\
\hline Use of emergeney contraceptives: & $113(52.1)$ \\
\hline Ihave used an emergency contraceptive before & \\
\hline The emergency contraceptive was recommended by: & $51(41.1)$ \\
\hline Frend & $37(30.3)$ \\
\hline Partner & $21(17.2)$ \\
\hline Health profensional & $17(13.9)$ \\
\hline Intemet & \\
\hline Reasons for using emergency contraceptivest & $33(27.3)$ \\
\hline Condom broke or slipped & $6(4.9)$ \\
\hline Missed pills & $13(10.6)$ \\
\hline Forced to have sex & $39(32.0)$ \\
\hline The withdrawal fail & $29(23.6)$ \\
\hline Timing miscalculation & \\
\hline & \\
\hline
\end{tabular}

Table 5: Mean Difference Analysis

\begin{tabular}{|c|c|c|c|c|c|c|c|}
\hline Variable & $\mathbf{s}$ & $\begin{array}{l}\text { Mean } \\
\text { Kearledge } \\
\text { Scare (SD) }\end{array}$ & $\begin{array}{l}95 \% \text { Canfidenes } \\
\text { Interval }\end{array}$ & Puralue & $\begin{array}{l}\text { Meas } \\
\text { Aeturde } \\
\text { Seare (SD) }\end{array}$ & $\begin{array}{l}95 \% \text { Canfidenes } \\
\text { Interial }\end{array}$ & Puralue \\
\hline Are $(\text { garan })^{*}$ & 93 & & & 0,76 & & & $0.8527+2$ \\
\hline$\frac{10-19}{20.24}$ & 439 & $\frac{12.02(2.72)}{15.5093)}$ & $\frac{14.05-1.36}{1486-1.54}$ & & $\frac{13.42(1.03)}{1.1 .3(1.64)}$ & $\frac{12.301-1.43}{1,03-1,34}$ & \\
\hline $25-28$ & 87 & $1.5 .06(1.31)$ & $1462-15.50$ & & $1.3 .22(1.70)$ & $12.81-1,64$ & \\
\hline$z^{30}$ & 12 & $14.53(2.15)$ & $19.22-15.95$ & & $13.42(1.31)$ & $12.59-14.25$ & \\
\hline Facalts: & & & & & & & \\
\hline Agrieshars & 54 & $15.35(2.21)$ & $14.75-15.95$ & 0.015 & $13.02(1.62)$ & $12.53-13.46$ & 0.147 \\
\hline Ant & 193 & $14.93(1.71)$ & $14.69-15.27$ & & $13.13(1.62)$ & $12.35-13.41$ & \\
\hline Bislaziel remen & 1.6 & 1.900 .039 & $1,46:-15397$ & & $1.3 .00(1.72)$ & $1.277-1.3 .40$ & \\
\hline Eductien & 39 & $149:(1.97)$ & $14.49-15.93$ & & $12.04(1.67)$ & 1258.1930 & \\
\hline Enginceting & 17 & $14.41(1.70)$ & $13.54-15.23$ & & $13.00(2.00)$ & $11.97-14.03$ & \\
\hline $\begin{array}{l}\text { Phempesutied } \\
\text { Sereng }\end{array}$ & 62 & $15.85(2.12)$ & $15.32-16.30$ & & $13.59(1.21)$ & $19.27-19.80$ & \\
\hline Vhyzieal Seimen & 18 & $14.28(2.05)$ & $13.26-15.30$ & & $12.67(1.75)$ & $11.90-1.3 .54$ & \\
\hline Sacelal Seienea & 1.27 & $15.12(1.89)$ & $14.79-15.45$ & & $13.30(1.74)$ & $12.90-13.60$ & \\
\hline Vetengn Medieins & 20 & $15.75(2.31)$ & $14.67-16.93$ & & $13.800 .89)$ & $13.99-14.22$ & \\
\hline Yar af Study" & & & & & & & \\
\hline $2 \pi d y z$ & 215 & $15.14(1.94)$ & $14.93-15.40$ & .0 .001 & $13.03(1.55)$ & $12.83-13.29$ & 0.772 \\
\hline 3ndyz & 160 & $14.95(2.02)$ & $14.64-15.25$ & & $13.22(1.75)$ & $12.96-13.49$ & \\
\hline $4^{2} y z$ & 213 & $14.90(1.92)$ & $14.73-15.25$ & & $13.21(1.66)$ & $12.90-13.44$ & \\
\hline$\frac{5 * y z}{y z}$ & 93 & $16.03(2.11)$ & $15.28-16.73$ & & $13.06(1.56)$ & $12.51-13.61$ & \\
\hline$g^{*} y^{z}$ & 5 & $13.00(1.22)$ & $16.43-10.52$ & & $13.80(1.10)$ & $12.44-15.16$ & \\
\hline Satamaling" & & & & & & & \\
\hline Nigenian & 627 & $15.11(1.99)$ & $-0.65-2.31$ & 0.273 & $19.17(1.64)$ & $-1.34-1.11$ & 0.951 \\
\hline Nan-Nizein & & $14.20(1.80)$ & & & $13.28(1.70)$ & & \\
\hline Deligian" & & & & & & & \\
\hline Shulim & 24 & $14.96(2.01)$ & $14.11-15.81$ & 0.007 & $12.96(1.30)$ & $12.41-13.51$ & 0.062 \\
\hline Remm Cuhalie & 300 & $15.32(2.02)$ & $15.10-15.55$ & & $13.35(1.62)$ & $13.17-19.53$ & \\
\hline Tretertent & 1.97 & $14.95(1.91)$ & $14.63-15.27$ & & $13.06(1.53)$ & $12.79-1.3 .33$ & \\
\hline other & 144 & $14.90(1.92)$ & $14.59-15.21$ & & $12.97(1.65)$ & $12.60-1.3 .24$ & \\
\hline Marital Statu" & & & & & & & \\
\hline Single & 566 & $15.07(1.99)$ & $14.91-15.24$ & 0.071 & $13.18(1.65)$ & $13.04-13.31$ & 0.794 \\
\hline $\begin{array}{l}\text { Caknation } \\
\text { bayfiend with }\end{array}$ & 25 & $15.44(2.49)$ & $14.44-16.44$ & & $13.16(1.52)$ & $12.53-13.78$ & \\
\hline Shamisd & 28 & $15.39(1.42)$ & $14.84 \cdot 15.44$ & & $12.82(1.49)$ & $12.24-1.3 .40$ & \\
\hline Schented & 4 & $1.75(0.50)$ & $11.95-19.55$ & & $13.00(2.16)$ & $9.56-16.44$ & \\
\hline Fams retting & 556 & $15.18(1.93)$ & $15.03-15.36$ & 0.393 & $1.3 .24(1.65)$ & $13.10-13.37$ & 0.267 \\
\hline Shangzzmeux & 41 & $1.7 .78(1.85)$ & $14.20-15.36$ & & $12.83(1.22)$ & $12.44-19.22$ & \\
\hline Dolyzemeux & 5 & $14.20(1.92)$ & $11.81-16.59$ & & $12.60(0.55)$ & $11.92-19.23$ & \\
\hline Solnest & 3 & $1.67(1.15)$ & $11.30-17.54$ & & $12.33(0.59)$ & $10.90-1.3 .77$ & \\
\hline $\begin{array}{l}\text { Phace of childaad } \\
\text { wobringing. }\end{array}$ & & 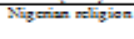 & & & & & \\
\hline Sous Wa: & 115 & $14.93(2.03)$ & $14.61-15.36$ & 0.776 & $12.87(1.81)$ & $12.64-19.31$ & 0.550 \\
\hline Seuth Eat & 373 & $15.16(1.97)$ & $14.96-15.36$ & & $13.24(1.51)$ & $13.03-13.39$ & \\
\hline South Sanh & 48 & $15.25(1.95)$ & $11.68-15.32$ & & $13.93(1.99)$ & $12.90-1.9 .95$ & \\
\hline Nath Weas & 17 & $14.33(1.73)$ & $13.90-15.77$ & & $12.82(1.70)$ & $12.95-13.70$ & \\
\hline Neth East & 28 & $15.54(1.84)$ & $14.32-16.25$ & & $13.18(1.47)$ & $12.61-13.75$ & \\
\hline Nath Cenenl & 36 & $15.00(2.23)$ & $14.25-15.75$ & & $13.23(1.61)$ & $12.79-13.82$ & \\
\hline Reaidenes" & & & & & & & \\
\hline Hertel & 430 & 15100097 & $-0.37-0.27$ & 0.775 & $1318(1.700$ & $-0.22-0.31$ & 0.766 \\
\hline of: compl & 504 & $15.4(1.79$ & & & $43.4(1.49$ & & \\
\hline
\end{tabular}

Tests: $a=A N O V A ; ~ b=$ Independent $t-t e s t, p \leq 0.05$ is statistically significant, $S D=$ standard deviation 
Knowledge, Attitudes and Use of Emergency Contraceptives among Female Students of the University

Table 6: Association between Demographic Variables and Knowledge, Attitudes towards Emergency Contraceptives

\begin{tabular}{|c|c|c|c|c|c|c|}
\hline Variables & $\begin{array}{l}\text { Poor } \\
\text { Knowledge }\end{array}$ & $\begin{array}{l}\text { Adequate } \\
\text { Knowledge }\end{array}$ & $\begin{array}{l}\text { P- } \\
\text { value }\end{array}$ & $\begin{array}{l}\text { Bad } \\
\text { Attitudes }\end{array}$ & $\begin{array}{l}\text { Good } \\
\text { Attitudes }\end{array}$ & P-value \\
\hline Residency & & & 0.855 & & & 0.696 \\
\hline Hostel & 256 & 174 & & 65 & 365 & \\
\hline Off-campus & 117 & 77 & & 27 & 167 & \\
\hline Faculty & & & $* 0.011$ & & & 0.085 \\
\hline $\begin{array}{l}\text { Agricultural } \\
\text { Sciences }\end{array}$ & 31 & 23 & & 9 & 45 & \\
\hline Arts & 83 & 50 & & 22 & 111 & \\
\hline $\begin{array}{l}\text { Biological } \\
\text { Sciences }\end{array}$ & 69 & 47 & & 21 & 95 & \\
\hline Education & 60 & 28 & & 16 & 72 & \\
\hline Engineering & 13 & 4 & & 4 & 13 & \\
\hline $\begin{array}{l}\text { Phammaceutical } \\
\text { Sciences }\end{array}$ & 24 & 38 & & 2 & 60 & \\
\hline $\begin{array}{l}\text { Physical } \\
\text { Sciences }\end{array}$ & 14 & 4 & & 2 & 16 & \\
\hline Social Sciences & 77 & 50 & & 17 & 110 & \\
\hline $\begin{array}{l}\text { Veterinary } \\
\text { Medicine }\end{array}$ & 10 & 10 & & 10 & 20 & \\
\hline
\end{tabular}

$* \mathrm{P} \leq 0.05$ 